\title{
Mother's Knowledge of Neonatal Danger Signs and Health-Seeking Practices and Associated Factors in Debretabor, Northwest Ethiopia: A Community-Based Cross-Sectional Study
}

This article was published in the following Dove Press journal:

Research and Reports in Neonatology

\author{
Azmeraw Ambachew Kebede (iD) \\ Endeshaw Admasu Cherkos ${ }^{2}$ \\ Eden Bishaw Taye' \\ 'Department of Clinical Midwifery, \\ School of Midwifery, College of Medicine \\ and Health Sciences, University of \\ Gondar, Gondar, Ethiopia; ${ }^{2}$ Department \\ of Women's and Family Health, School of \\ Midwifery, College of Medicine and \\ Health Sciences, University of Gondar, \\ Gondar, Ethiopia
}

Background: Neonatal mortality is still unacceptably high in Ethiopia. One key strategy to cut back neonatal mortality is increasing the mother's knowledge of neonatal danger signs and health-seeking practices. This study assessed mother's knowledge of neonatal danger signs and health-seeking practices and associated factors in Debretabor town, Northwest Ethiopia.

Methods: A community-based cross-sectional study was conducted from July 1st to August 10th in Debretabor town, northwest Ethiopia and cluster sampling technique was used to select 772 mothers. A semi-structured, pretested and interviewer-administered questionnaire was employed. Data were entered into epi info version 7 and analyzed by SPSS 23 . Multivariable logistic regression model was fitted to identify factors associated with' mother's knowledge of neonatal danger signs and health-seeking practices. Odds ratio with $95 \%$ confidence interval was computed to determine the level of significance.

Results: Mother's knowledge of neonatal danger signs and health-seeking practices was 36.5\% (95\% CI: 33, 40) and 78.7\% (95\% CI: 72.9, 83.7) respectively. Media exposure $(\mathrm{AOR}=2.85 ; 95 \% \mathrm{CI}: 1.47,5.53)$, birth preparedness $(\mathrm{AOR}=9.06 ; 95 \% \mathrm{CI}: 5.99,13.7)$, husband involvement $(\mathrm{AOR}=1.45 ; 95 \% \mathrm{CI}: 1.04,2.11)$, increased parity $(\mathrm{AOR}=2.46 ; 95 \%$ CI: $1.16,5.19)$, whose neonate developed danger signs ( $A O R=1.83 ; 95 \%$ CI: $1.25,2.67)$ and higher educational status ( $\mathrm{AOR}=2.88 ; 95 \% \mathrm{CI}: 1.45,5.69)$ were factors significantly associated with mother's knowledge of neonatal danger signs. Furthermore, having good knowledge of neonatal danger signs $(\mathrm{AOR}=4.0 ; 95 \% \mathrm{CI}: 1.63,9.8)$, being autonomous $(\mathrm{AOR}=4.35 ; 95 \% \mathrm{CI}: 1.63,11.6)$, media exposure (AOR=3.06; 95\% CI: 1.08, 8.63), and husband involvement $(\mathrm{AOR}=3.53 ; 95 \% \mathrm{CI}: 1.49,8.33)$ were factors statically significant with health-seeking practices of mothers for neonatal danger signs.

Conclusion: Our findings show that maternal knowledge of neonatal danger signs was low. Promotion of mother's decision-making power, birth preparedness, husband involvement and mass media throughout the maternal continuum of care will have a great role in improving mother's knowledge of neonatal danger signs and health-seeking practices.

Keywords: Ethiopia, danger signs, health-seeking practice, knowledge, newborns

\section{Introduction}

Neonatal danger signs (NDS) refer to the experience of clinically detected signs that might indicate a high risk of neonatal morbidity and mortality and the need for timely medical treatment or therapeutic intervention. ${ }^{1,2}$ The first twenty-eight days of neonatal life comprise an extremely critical period for the survival of neonates; ${ }^{3}$
Correspondence: Azmeraw Ambachew Kebede

Po. Box 196 Gondar, Ethiopia

Tel +251910880232

Email azmuzwagholic@gmail.com 
as a result, it is the foremost endangered period due to which neonates undergo many physiological and environmental changes to adapt to the extra-uterine life. ${ }^{3,4}$

Globally, 2.6 million neonates ended up with preventable death within the initial 4 weeks of life; ${ }^{4,5}$ properly accounting for $46 \%$ of all under-five mortality. ${ }^{5}$ Africa represents $25 \%$ of the global neonatal death. ${ }^{6}$ Five countries including Ethiopia accounted for half of the world's neonatal death. ${ }^{5}$ Recent data in Ethiopia showed that the neonatal mortality rate is 30 per 1000 live births. ${ }^{7}$

According to World Health Organization's 2013 key recommendations, high-grade fever, fast breathing, hypothermia, severe chest indrawing, convulsion, unconsciousness, jaundice in the 1 st 24 hours/involving the palm and sole, lethargy, umbilical redness or pus drainage and unable to breastfeed are danger signs for a neonate. ${ }^{8}$ Some other studies reported that diarrhea and pus drainage from the eye are considered as neonatal danger signs. ${ }^{9-12}$

Mother's knowledge of neonatal danger signs and healthseeking practices is low in resource-limited countries. ${ }^{13}$ Lack of formal links between the local community and health facilities contributes to the inadequate level of mother's knowledge of neonatal danger signs and health-seeking practices. ${ }^{14}$ Similarly, the lack of decision-making power of mothers on maternal and neonatal healthcare utilization remains an important drawback in developing countries. ${ }^{15}$

Evidence recommends that there is a need to increase awareness on NDS through the continuum of care to improve mother's knowledge of neonatal danger signs. ${ }^{16-}$

${ }^{18}$ However, there is negligence of health professionals to create awareness on neonatal danger sign in the real world. The effective provision of compassionate and respectful care throughout all the continuum of care will increase the conscious intention of the mother's health-seeking practices for neonatal illness. ${ }^{16}$ Besides, knowledge and healthseeking practice of mothers on neonatal danger signs are the best indicators of accessibility and quality of care provided by health professionals. ${ }^{19}$

So far, studies in Enugu state in Nigeria, Uganda, Baghdad in Iran, and Ethiopia; Ambo town, Fogera district, Gondar town, Mekelle city, Woldia General hospital, Chencha district, and East Hararge zone revealed that mother's knowledge of neonatal danger signs were inconsistent which was $78.7 \%{ }^{12}$ $14.8 \%{ }^{20} \quad 81 \%{ }^{18} \quad 20.3 \%,{ }^{17} 64.1 \%,{ }^{21} \quad 18.2 \%,{ }^{22} \quad 50.6 \%,{ }^{23}$ $11.7 \%,{ }^{9} 50.3 \%{ }^{24}$ and $9.38 \%{ }^{25}$ respectively.

Generally, improving newborns and children health is a national and global agenda that comprises the third component of the sustainable development goals (SDG). ${ }^{26}$
Consequently, improving the health of a newborn and reducing their mortality will play a great role in the achievement of the SDG. This could be achieved by identifying factors affecting a mother's knowledge of neonatal illness and health-seeking practices. Even though researches were conducted on mother's knowledge of neonatal danger signs and health-seeking practices in Ethiopia, the currently conducted researches failed to address some variables like birth preparedness, husband involvement in maternal, neonatal and children health $(\mathrm{MNCH})$, history of neonatal death, the role of health extension workers (HEWs) and mother's autonomy in $\mathrm{MNCH}$ care utilization in common.

Despite the fact Ethiopia has properly designed a strategy for the improvement of neonatal health, there is still a high burden of neonatal death. ${ }^{7}$ Early detection and effective management of a neonatal problem represent a key strategy to reduce neonatal mortality. Therefore, this study assessed knowledge of neonatal danger signs and health-seeking practices and associated factors among mothers who gave birth in the last 1 year in Debretabor town, northwest Ethiopia.

\section{Methods}

\section{Study Design, Setting and Period}

A community-based cross-sectional study was conducted from July 1st to August 10th, 2019 in Debretabor town, northwest Ethiopia. The town is located at $665 \mathrm{~km}$ from Addis Ababa, the capital city of Ethiopia and $103 \mathrm{~km}$ from Bahir Dar (the capital city of Amhara regional state). Currently, the town has a total population of 63,563, of whom, more than half $(54.8 \%)$ were female. An estimated 19,327 are reproductive-aged women. About 4317 (6.8\%) are under five. Also, the town has one general hospital, three health centers, 6 Health posts and 6 private clinics (Debretabor administrative town report, unpublished data).

\section{Study Population}

All mothers who gave birth in the last year and had an infant age of 29 to 365 days in the selected clusters during the data collection period were included. Mothers who were seriously ill throughout the data collection period were excluded.

\section{Sample Size Determination and Sampling Procedure}

The sample size for this study was determined by using a single population proportion formula by considering the 
assumptions: $5 \%$ margin of error, $95 \%$ level of confidence, $32 \%$ knowledge of mothers on NDS. ${ }^{10}$

$$
\begin{aligned}
n & =\frac{(z \alpha / 2)^{2} * p(1-p)}{d^{2}}=\frac{(1.96)^{2} * 0.32(1-0.32)}{(0.05) 2} \\
& =.335
\end{aligned}
$$

where $\mathrm{n}=$ required sample size, $\alpha=$ level of significant, $\mathrm{z}=$ standard normal distribution curve value for $95 \%$ confidence level $=1.96, \mathrm{P}=$ proportion of mother's knowledge about neonatal danger sign, $\mathrm{d}=$ margin of error. By considering a design effect of $2 \%$ and $10 \%$ non-response rate the final sample size was 737. Debretabor town has six "kebeles" (which is the smallest administrative unit in Ethiopia) and three "kebeles" were selected by simple random sampling. House-to-house visit was carried out in the selected clusters to identify eligible mothers. All eligible mothers in the selected clusters were interviewed. Finally, because of the cluster effect, 772 mothers were interviewed [Figure 1].

\section{Measurements}

\section{Good Knowledge of Neonatal Danger Signs}

Mothers who were able to mention at least 3 neonatal danger signs among the 12 neonatal danger signs without prompt. $^{10,17,21}$

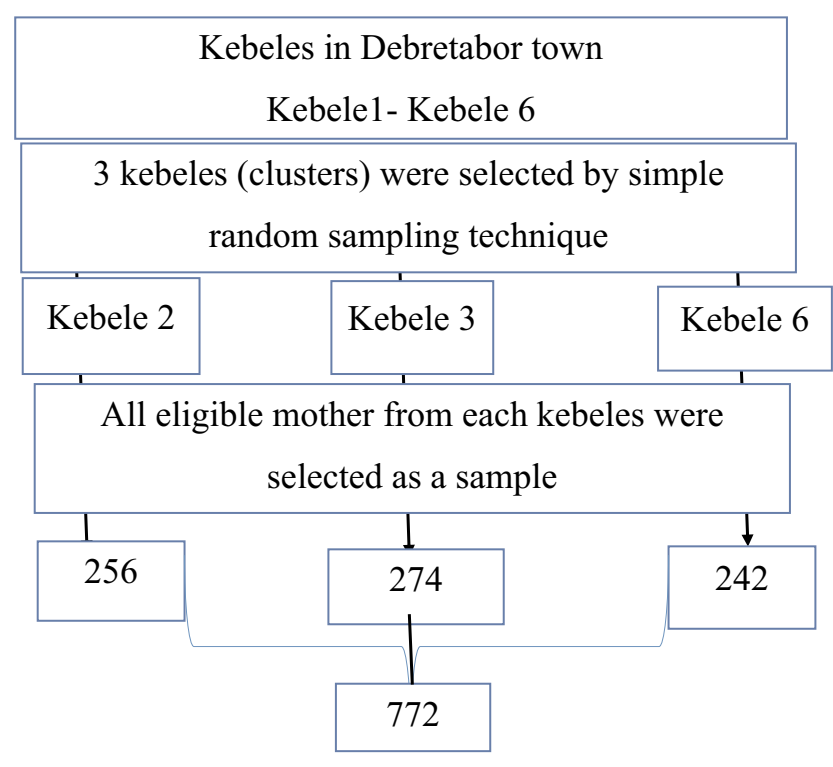

Figure I Schematic presentation of the sampling procedure for the study knowledge of mothers on neonatal danger signs and health-seeking practices and associated factors among women who gave birth in the last one year in Debretabor town, northwest Ethiopia 2019.

\section{Appropriate Health-Seeking Practices}

Mothers who sought care for neonatal danger signs from well-qualified health professionals in governmental and/or private health facilities. $^{27,28}$

\section{Inappropriate Health-Seeking Practices}

Mothers who sought care for neonatal danger signs other than qualified health professionals like purchasing over the counter drugs, treating by home remedies, seeking care from temples and traditional healers. ${ }^{27,28}$

\section{Adequate Birth Preparedness}

A mother was considered adequately prepared for birth and its complication if she was able to identify four components from birth preparedness and complication readiness items spontaneously. ${ }^{29,30}$

\section{Data Collection Tools and Procedures}

Data were collected using a semi-structured intervieweradministered questionnaire. Three male diploma and bachelor of science in midwifery degree holders, trained about the interview technique, collected the data.

\section{Data Quality Control}

The questionnaire was first prepared in English and translated to Amharic language and back to English to maintain the consistency of the questionnaire. Before the actual data collection, pretest was done on $5 \%$ of the sample size at Woreta town to check response, language clarity, and appropriateness of the questionnaire. During data collection, the questionnaire was checked for completeness daily by the supervisors.

\section{Data Processing and Analysis}

Data were checked, coded and entered into EPI INFO version 7, and were exported to SPSS version 23 for analysis. Descriptive statistics were used to present participants' characteristics, level of knowledge and health-seeking practice. Binary logistic regression was fitted to identify statistically significant independent variables and variables having a p-value of less than 0.2 were included in the multivariable logistic regression for controlling confounders. In multivariable logistic regression, a p-value of $<0.05$ with $95 \%$ CI for odds ratio was used to determine significance association.

\section{Ethics Approval and Consent to Participate}

The study was conducted in accordance with the Ethiopian Health Research Ethics Guideline and the declaration of 
Helsinki. Ethical clearance was obtained from the University of Gondar College of Medicine and Health Sciences ethical review committee. A formal letter of administrative approval was obtained from Debretabor town health office. A written informed consent was taken from each of the study participants after a clear explanation of the aim of the study.

\section{Result}

\section{Socio-Demographic Characteristics of Study Participant}

A total of 772 mothers were interviewed, resulting in $100 \%$ response rate. The mean age of the study participants was 30 years $(\mathrm{SD} \pm 5.96)$ and $56.9 \%$ of the participant's age were between the age group of 25-34 years. Most (96.6\%) respondents were Orthodox Christian by religion. About $94.6 \%$ of the participants were married and $364(47.1 \%)$ of them had accomplished diploma and above education. Nearly half (48.7\%) of the study participants were housewives by occupation. Regarding the occupation of the husband $55.7 \%$ were government employees and two-third (66.6\%) of them had completed college and above education. Almost three-fourths of the study participants have a family size of three to five [Table 1].

\section{Reproductive History and Maternity Healthcare Service-Related \\ Characteristics}

From the total study participants, 506 (65.5\%) mothers had a parity of two to four. The majority (94.2\%) of mothers had at least one ANC visit in their recent pregnancy. Six hundred and ten (79\%) mothers deliver at a government hospital for their recent delivery. Most (92.1\%) of mothers had at least one postnatal visit for their most recent delivery. Nearly one-fourth (24\%) of the mothers were adequately prepared for their recent delivery and about (44\%) of study participants got the husband's involvement in maternity and childcare-related activities [Table 2].

\section{Mother's Knowledge of Neonatal Danger Signs and Health-Seeking Practices}

Mother's knowledge of neonatal danger sign was $36.5 \%$ (95\% CI; 33, 40). Fever (53.9\%), diarrhea (43.7\%) and inability to suck (37\%) were the commonly mentioned danger signs by the study participants [Figure 2]. Among the
Table I Socio-Demographic Characteristics of Study Participants in Debretabor Town, Northwest Ethiopia, 2019 $(n=772)$

\begin{tabular}{|c|c|c|}
\hline Charactestics & Frequency & Percentage \\
\hline \multicolumn{3}{|l|}{ Age of mothers in year } \\
\hline $18-24$ & 128 & 16.6 \\
\hline $25-34$ & 439 & 56.9 \\
\hline$\geq 35$ & 205 & 26.5 \\
\hline \multicolumn{3}{|l|}{ Religion } \\
\hline Orthodox Christian & 746 & 96.6 \\
\hline Muslim & 16 & 2.1 \\
\hline Protestant & 10 & 1.3 \\
\hline \multicolumn{3}{|l|}{ Current marital status } \\
\hline Married & 730 & 94.6 \\
\hline Unmarried & 42 & 5.4 \\
\hline \multicolumn{3}{|l|}{ Educational status of the mother's } \\
\hline No formal education & 84 & 10.9 \\
\hline Primary education & 148 & 19.2 \\
\hline Secondary education & 176 & 22.8 \\
\hline Diploma and above & 364 & 47.1 \\
\hline \multicolumn{3}{|l|}{ Occupation of the mother's } \\
\hline Housewife & 376 & 48.7 \\
\hline Government employee & 226 & 29.3 \\
\hline Self employed & 29 & 3.8 \\
\hline Merchant & 102 & 13.2 \\
\hline Student & 39 & 5 \\
\hline \multicolumn{3}{|l|}{ Husband educational status ( $n=730)$} \\
\hline No formal education & 19 & 2.6 \\
\hline Primary & 66 & 9 \\
\hline Secondary & 159 & 21.8 \\
\hline Diploma and above & 486 & 66.6 \\
\hline \multicolumn{3}{|l|}{ Husband occupation $(n=730)$} \\
\hline Government employee & 407 & 55.7 \\
\hline Merchant & 156 & 21.4 \\
\hline Self employed & 115 & 15.7 \\
\hline Daily labor & 45 & 6.2 \\
\hline Student & 7 & 1 \\
\hline \multicolumn{3}{|l|}{ Exposure to media } \\
\hline Yes & 656 & 85 \\
\hline No & 116 & 15 \\
\hline \multicolumn{3}{|l|}{ Family size } \\
\hline$<3$ & 15 & 1.9 \\
\hline $3-5$ & 582 & 75.4 \\
\hline$>5$ & 175 & 22.7 \\
\hline \multicolumn{3}{|l|}{$\begin{array}{l}\text { Average monthly income of the } \\
\text { family }\end{array}$} \\
\hline$<1200$ ETB & 50 & 6.5 \\
\hline I20I-3000 ETB & 264 & 34.2 \\
\hline $300 \mathrm{I}-5000$ ETB & 248 & 32.1 \\
\hline$>5000$ ETB & 210 & 27.2 \\
\hline
\end{tabular}


Table 2 Reproductive and Maternity Health Care Service Characteristics of Study Participants in Debretabor Town, Northwest Ethiopia, $2019(n=772)$

\begin{tabular}{|c|c|c|}
\hline Characteristics & Frequency & Percentage \\
\hline \multicolumn{3}{|l|}{ Parity } \\
\hline 1 & 214 & 27.7 \\
\hline $2-4$ & 506 & 65.5 \\
\hline$>4$ & 52 & 6.8 \\
\hline \multicolumn{3}{|l|}{ Had ANC } \\
\hline Yes & 727 & 94.2 \\
\hline No & 45 & 5.8 \\
\hline \multicolumn{3}{|l|}{ Number of ANC follow up $(n=727)$} \\
\hline$<4$ & 289 & 39.8 \\
\hline$\geq 4$ & 438 & 60.2 \\
\hline \multicolumn{3}{|l|}{ Place of delivery } \\
\hline Government hospital & 610 & 79 \\
\hline Health center & 115 & 14.9 \\
\hline Private hospital/clinic & 12 & 1.5 \\
\hline At home & 35 & 4.6 \\
\hline \multicolumn{3}{|l|}{ Birth assistant } \\
\hline Health professionals & 737 & 95.5 \\
\hline Traditional birth attendants & 35 & 4.5 \\
\hline \multicolumn{3}{|c|}{$\begin{array}{l}\text { Advice on neonatal danger signs after } \\
\text { delivery }\end{array}$} \\
\hline Yes & 570 & 73.8 \\
\hline No & 202 & 26.2 \\
\hline \multicolumn{3}{|l|}{ Had PNC } \\
\hline Yes & 711 & 92.1 \\
\hline No & 61 & 7.9 \\
\hline \multicolumn{3}{|l|}{ Number of PNC $(n=7 \mid I)$} \\
\hline$<3$ & 291 & 40.9 \\
\hline$\geq 3$ & 420 & 59.1 \\
\hline \multicolumn{3}{|l|}{ Birth preparedness } \\
\hline Adequately prepared & 185 & 24 \\
\hline Not adequately prepared & 587 & 76 \\
\hline \multicolumn{3}{|l|}{ Husband/partner involvement } \\
\hline Involved & 340 & 44 \\
\hline Not involved & 432 & 56 \\
\hline \multicolumn{3}{|l|}{ Visited by HEWs after delivery } \\
\hline Yes & 424 & 54.9 \\
\hline No & 348 & 45.1 \\
\hline \multicolumn{3}{|l|}{ History of neonatal death } \\
\hline Yes & 27 & 3.5 \\
\hline No & 745 & 96.5 \\
\hline \multicolumn{3}{|l|}{ Time taken to the health facility } \\
\hline$<30$ minute & 754 & 97.7 \\
\hline$\geq 30$ minute & 18 & 2.3 \\
\hline \multicolumn{3}{|l|}{ Mother's autonomy } \\
\hline Highly autonomous & 601 & 77.8 \\
\hline Less autonomous & $17 \mid$ & 22.2 \\
\hline
\end{tabular}

study participants whose neonate developed danger signs, $78.7 \%$ sought appropriate healthcare practices $(95 \% \mathrm{CI}$ : 72.9, 83.7) [Figure 3].

\section{Reasons for Not Seeking Appropriate Healthcare for Neonatal Danger Signs}

About $21.3 \%$ of mothers had inappropriate health-seeking practices for neonatal danger signs. The most commonly mentioned reasons by the mothers who did not take sick neonates to the health facilities were illness was not serious, illness caused by evil spirits and considering herbs as more effective treatment [Figure 4].

\section{Factors Associated with Mother's Knowledge of Neonatal Danger Signs and Health-Seeking Practices}

From the multivariable logistic regression analysis mothers whose recent baby developed danger signs, educational status of the mother, exposure to mass media, parity, birth preparedness and husband involvement in $\mathrm{MNCH}$ related activities were significantly associated withmother's knowledge of neonatal danger signs.

Mothers who had mass media exposure were 2.85 times more likely to have had adequate knowledge of neonatal danger signs compared to mothers who did not have exposure $(\mathrm{AOR}=2.85 ; 95 \% \mathrm{CI}: 1.47,5.53)$. Mothers who gave birth for more than four times were 2.46 times more likely to have had adequate knowledge of neonatal danger signs compared to those mothers who deliver only once $(\mathrm{AOR}=2.46$; 95\% CI: 1.16, 5.19). Similarly, the odds of having good knowledge of neonatal danger signs among mothers who had adequate birth preparedness were nine $(\mathrm{AOR}=9.06$; $95 \%$ CI: $5.99,13.7)$ times compared with their counterparts. This study also revealed that mothers who got partner and/or husband involvement in $\mathrm{MNCH}$ related activities were 1.45 times to have good knowledge of neonatal danger signs compared to their counterparts ( $\mathrm{AOR}=1.45 ; 95 \% \mathrm{CI}$ : 1.04 , 2.11). Likewise, the odds of having adequate knowledge of neonatal danger signs among mothers who attend diploma and above education were 2.88 times more than those who had no formal education ( $\mathrm{AOR}=2.88$; $95 \% \mathrm{CI}$ : 1.45, 5.69). Moreover, mother's whose current baby developed danger signs were 1.83 times more likely to know about neonatal danger signs ( $\mathrm{AOR}=1.83 ; 95 \% \mathrm{CI}$ : 1.25, 2.67) [Table 3].

On the multivariable logistic regression analysis mother's knowledge of neonatal danger signs, mother's decision-making power, husband and/or partner involvement and exposure 


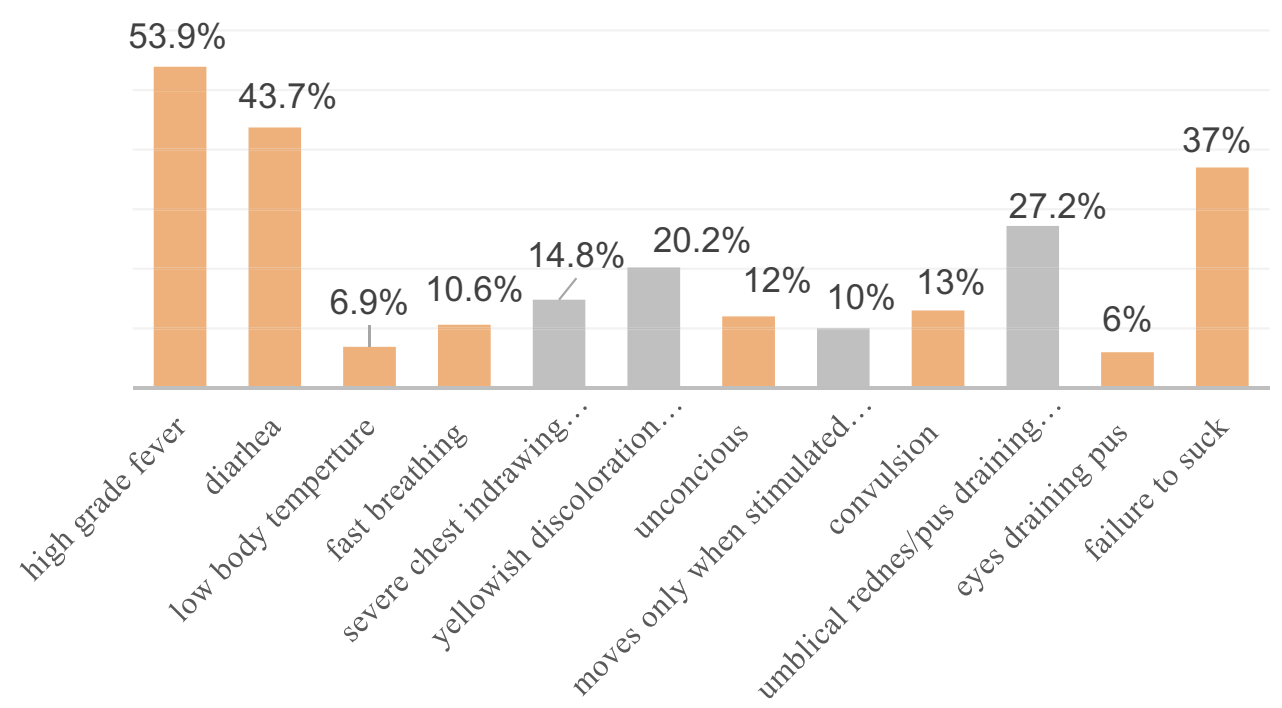

Figure 2 Knowledge on each neonatal danger signs among mother's who gave birth in the last one year in Debretabor town, northwest Ethiopia, 2019.

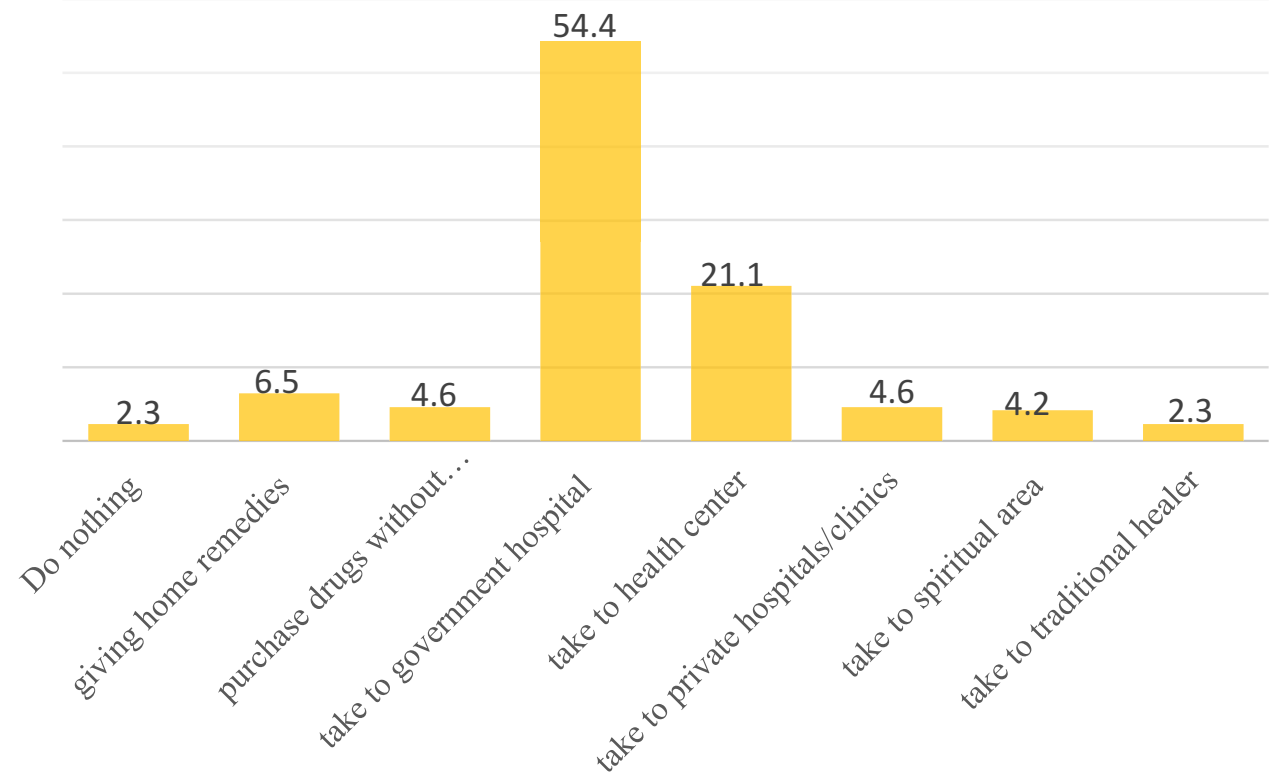

Figure 3 Actions taken by mothers for neonatal danger signs among mother's who gave birth in the last one year in Debretabor town, northwest Ethiopia, 2019.

to media were independently associated with the healthseeking practice of mothers for NDS. The odds of having appropriate health-seeking practices among mothers who had good knowledge of neonatal danger sign were four times $(\mathrm{AOR}=4.00 ; 95 \% \mathrm{CI}: 1.63,9.80)$ compared to mothers who had poor knowledge. This study found that autonomous mothers were 4.35 times more likely to have appropriate health-seeking practices for neonatal danger signs compared to their counterparts ( $\mathrm{AOR}=4.35 ; 95 \% \mathrm{CI}: 1.63,11.6$ ). Similarly, the odds of having appropriate health-seeking practices for neonatal danger signs among mothers who were exposed to media were three times than those who did not use media (AOR=3.06; 95\% CI: 1.08, 8.63). Likewise, mothers who had partner and/or husband involvement in MNCH services were 3.53 times more likely to have proper health-seeking practices for neonatal danger signs compared to their counterparts (AOR $=3.53 ; 95 \% \mathrm{CI}: 1.49,8.33$ ) [Table 4].

\section{Discussion}

The present study assessed mother's knowledge of neonatal danger signs and health-seeking practices and associated 


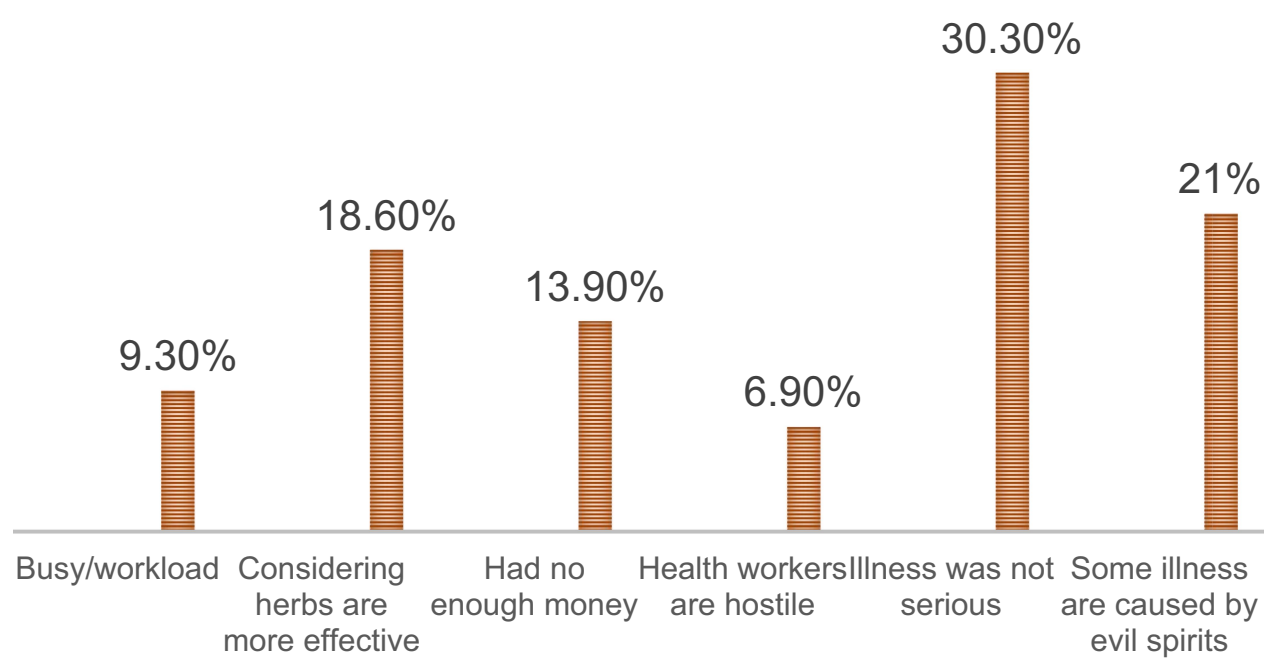

Figure 4 Reasons why mothers did not take their sick neonates to the health institution among mother's who gave birth in the last one year in Debretabore town, northwest Ethiopia, 2019.

factors in northwest Ethiopia. More than a third of mothers had sufficient knowledge of neonatal danger signs and about three-fourths of them had appropriate healthcare-seeking practice for neonatal danger signs. Mother's educational status, most recent baby developed danger signs, exposure to media, higher parity, birth preparedness, mother's decision-making power and husband involvement in $\mathrm{MNCH}$ were significant predictors of mother's knowledge of neonatal danger signs and healthcare-seeking for NDS.

We found that mother's knowledge of neonatal danger signs was $36.5 \%$, which was higher than findings from previous researches conducted in Ghana, ${ }^{34}$ Nigeria, ${ }^{35}$ Kenya, $^{36}$ Uganda $^{20}$ and similar studies elsewhere in Ethiopia including Wolkite, ${ }^{10}$ Ambo, ${ }^{17}$ Gondar, ${ }^{22}$ and Woldia towns. ${ }^{9}$ This discrepancy might be due to differences in the study period, socio-cultural characteristics, study setting and defining the outcome variable. In this study, nearly half of the study participants were diploma and above by education. The high proportion of mothers with good knowledge of neonatal danger sign in the current study might be an enabling factor for mother's knowledge of neonatal danger signs. Maternal education is found to be an enabling factor for the mother to have good knowledge of neonatal danger signs from studies elsewhere. ${ }^{9,17,22,33}$ Knowledge of danger signs for mothers is enhanced by delivery by a skilled birth attendant, ${ }^{33}$ being an urban resident, ${ }^{9,33}$ having ANC and PNC visit. ${ }^{9,22}$

The level of mother's knowledge of neonatal danger sign was, however, lower than findings from studies based in Nigeria, ${ }^{12}$ Baghdad, ${ }^{18}$ and in parts of Ethiopia including Mekelle town, ${ }^{23}$ Chencha district ${ }^{24}$ and Fogera district. ${ }^{21}$
The variation might be due to differences in the provision of information on neonatal danger signs and the time gap. Another explanation might be because of the unprompted questions we used to assess neonatal danger signs in this study.

Our finding showed the health-seeking practice of mothers for neonatal danger signs was $78.7 \%$, which was higher than reports from Nigeria, ${ }^{12}$ Bangladesh, ${ }^{4,45}$ and Baghdad in Iraq. ${ }^{18}$ This report was also higher than previous studies conducted in Ethiopia such as in Ambo town, ${ }^{17}$ Tenta district, ${ }^{28}$ and Wolkite town. ${ }^{10}$ The high proportion of mothers' health-seeking practices for neonatal danger sign might be due to the presence of good enabling factors (for example, delivery in a health facility), ${ }^{10,31}$ socio-cultural differences of the study population and the higher level of knowledge about neonatal danger signs. Because knowledge is an entry point for any healthcare-seeking behavior, it is expected that mothers with sufficient knowledge of neonatal danger signs are more likely to better healthcare-seeking practices.

The present study found that mothers who had an educational level of diploma and above education were nearly 3 times higher odds of being knowledgeable compared to those with no formal education. This is in agreement with previous studies conducted in Ethiopia. ${ }^{17,33}$ This is explained by the fact that educated mothers are more likely to utilize maternal and neonatal healthcare services, are economically capable (thus able to use broadcasting devices like television, radio and magazine) and utilize maternal and neonatal health information than others. 
Table 3 Bivariable and Multivariable Logistic Regression Analysis of Factors Associated with Mother's Knowledge on Neonatal Danger Sign in Debretabor Town, Northwest Ethiopia, 2019 ( $n=772)$

\begin{tabular}{|c|c|c|c|c|}
\hline \multirow[t]{2}{*}{ Variables } & \multicolumn{2}{|c|}{ Knowledge of mother's } & \multirow[t]{2}{*}{ COR $(95 \% \mathrm{Cl})$} & \multirow[t]{2}{*}{ AOR $(95 \% \mathrm{Cl})$} \\
\hline & Good & Poor & & \\
\hline \multicolumn{5}{|l|}{ Birth preparedness } \\
\hline Adequately prepared & 142 & 43 & $10.5(7.14,15.6)$ & $9.06(5.99,13.7) * *$ \\
\hline Inadequately prepared & 140 & 447 & 1 & I \\
\hline \multicolumn{5}{|l|}{ husband involvement } \\
\hline Involved & 159 & $|8|$ & $2.2(1.64,2.97)$ & $1.45(1.04,2.11) *$ \\
\hline Not involved & 123 & 309 & 1 & 1 \\
\hline \multicolumn{5}{|l|}{ Parity } \\
\hline I & 65 & 149 & 1 & I \\
\hline $2-4$ & 193 & 313 & $\mathrm{I} .4 \mathrm{I}(\mathrm{I} .004, \mathrm{I} .99)$ & I.2 $(0.78, I .78)$ \\
\hline$>4$ & 24 & 28 & $1.96(1.06,3.65)$ & $2.46(1.16,5.19)^{*}$ \\
\hline \multicolumn{5}{|l|}{ Mother's occupation } \\
\hline Housewife & 115 & 261 & 1 & 1 \\
\hline Government employee & 107 & 119 & $2.04(1.45,2.87)$ & $1.36(0.82,2.24)$ \\
\hline Self employed & 10 & 19 & $1.2(0.54,2.65)$ & $1.0(0.40,2.47)$ \\
\hline merchant & 42 & 60 & $1.6(1.01,2.45)$ & $1.68(0.97,2.9)$ \\
\hline student & 8 & 31 & $0.59(0.26, \mid .31)$ & $0.49(0.2,1.35)$ \\
\hline \multicolumn{5}{|c|}{ Average monthly income } \\
\hline$<1200$ & 12 & 38 & 1 & I \\
\hline$|20|-3000$ & 80 & 184 & $1.38(0.68,2.77)$ & $0.76(0.34,1.7)$ \\
\hline $300 I-5000$ & 106 & 142 & $2.36(1.18,4.74)$ & $0.64(0.28,1.47)$ \\
\hline$>5001$ & 84 & 126 & $2.11(1.04,4.27)$ & $0.42(0.17,1.04)$ \\
\hline \multicolumn{5}{|c|}{ Educational status of the mother's } \\
\hline No formal education & 17 & 67 & 1 & 1 \\
\hline Primary education & 43 & 105 & $1.61(0.85,3.06)$ & $1.95(0.94,4.08)$ \\
\hline Secondary education & 54 & 122 & $1.74(0.94,3.25)$ & $1.79(0.91 .-3.88)$ \\
\hline Diploma and above & 168 & 196 & $3.38(1.90,5.58)$ & $2.88(1.45,5.69)^{*}$ \\
\hline \multicolumn{5}{|l|}{ Maternal age in year } \\
\hline 18- 24 & 35 & 93 & I & 1 \\
\hline $25-34$ & 172 & 267 & $1.71(1.11,2.64)$ & $0.87(0.49,1.57)$ \\
\hline$\geq 35$ & 75 & 130 & $1.53(0.95,2.48)$ & $0.68(0.34,1.36)$ \\
\hline \multicolumn{5}{|l|}{ Marital status } \\
\hline Married & 275 & 455 & $3.02(1.32,6.89)$ & $2.07(0.72,5.97)$ \\
\hline Unmarried & 7 & 35 & 1 & 1 \\
\hline \multicolumn{5}{|l|}{ Exposure to media } \\
\hline Exposed & 267 & 389 & $4.62(2.63,8.13)$ & $2.85(1.47,5.53) *$ \\
\hline unexposed & 15 & 101 & 1 & 1 \\
\hline \multicolumn{5}{|c|}{ Neonates develop danger signs } \\
\hline Yes & 113 & 108 & $2.36(1.72,3.26)$ & I.83 $(1.25,2.67) * *$ \\
\hline No & 169 & 382 & 1 & I \\
\hline
\end{tabular}

Notes: *P value $<0.001$, **p value $<0.05$, I reference category.

Birth preparedness and complication readiness is an important determinant factor for a mother's knowledge of neonatal danger signs. Mothers who had adequate birth preparedness were nine times more likely to be knowledgeable compared to those mothers who had not adequate birth preparedness. This result is consistent with studies 
Table 4 Bivariable and Multivariable Logistic Regression Analysis of Factors Associated with Mother's Health-Seeking Practices for Neonatal Danger Sign in Debretabor Town, Northwest Ethiopia, $2019(n=221)$

\begin{tabular}{|c|c|c|c|c|}
\hline \multirow[t]{2}{*}{ Variables } & \multicolumn{2}{|c|}{ Appropriate Health seeking practice } & \multirow[t]{2}{*}{ COR $(95 \% \mathrm{Cl})$} & \multirow[t]{2}{*}{ AOR (95\%Cl) } \\
\hline & Yes & No & & \\
\hline \multicolumn{5}{|l|}{ Birth preparedness } \\
\hline Adequately prepared & 75 & 6 & $5.2(2.1,12.8)$ & $2.1(0.73,6.2)$ \\
\hline Inadequately prepared & 99 & 41 & 1 & 1 \\
\hline \multicolumn{5}{|c|}{ Partner/husband involvement } \\
\hline Involved & 113 & 10 & $6.85(3.2,14.7)$ & $3.53(1.49,8.33) *$ \\
\hline Not involved & 61 & 37 & I & 1 \\
\hline \multicolumn{5}{|l|}{ Knowledge of mother's } \\
\hline Knowledgeable & 105 & 8 & $7.4(3.3,16.8)$ & $4.0(1.63,9.80) * *$ \\
\hline Not knowledgeable & 69 & 39 & I & 1 \\
\hline \multicolumn{5}{|l|}{ Mother's autonomy } \\
\hline Highly autonomous & 162 & 12 & $9.16(4.01,18.9)$ & $4.35(I .63, I I .6) *$ \\
\hline Less autonomous & 28 & 19 & 1 & 1 \\
\hline \multicolumn{5}{|l|}{ Exposure to media } \\
\hline Exposed & 164 & 10 & II.I (4.7,23.6) & $3.06(1.08,8.63) *$ \\
\hline Unexposed & 28 & 19 & I & 1 \\
\hline \multicolumn{5}{|l|}{ Visited by HEWs } \\
\hline Yes & 123 & 51 & $2.74(1.4,5.3)$ & $0.9(0.33,2.5)$ \\
\hline No & 22 & 25 & I & 1 \\
\hline \multicolumn{5}{|c|}{ Educational status of mother's } \\
\hline No formal education & 15 & 7 & I & I \\
\hline Primary & 21 & 16 & $0.61(0.2,1.85)$ & $0.7(0.18,2.74)$ \\
\hline Secondary & 35 & 8 & $2.04(0.63,6.6)$ & I.46 $(0.37,5.76)$ \\
\hline Diploma and above & 103 & 16 & $3.0(1.06,8.5)$ & $0.9(0.26,3.16)$ \\
\hline
\end{tabular}

Notes: *P $\leq 0.05$, **P $\leq 0.001$.

Abbreviations: AOR, adjusted odd ratio; COR, crude odd ratio; $\mathrm{Cl}$, confidence interval; HEWs, health extension workers; I, reference category.

conducted in Mekelle town, Ethiopia ${ }^{23}$ and Uganda. ${ }^{20}$ One explanation is that being birth prepared is a clue that mothers are aware of the threats related to pregnancy and childbirth and considerably related to the use of experienced birth attendants. ${ }^{37}$ Another reason could be, birth preparedness encourages mothers to inquire about information regarding the neonatal health through the continuum of care, which improves healthcare-seeking practice.

The present study also found that those mothers who got their husband involved in $\mathrm{MNCH}$ - related services were 1.45 times more likely to have had good knowledge of neonatal danger signs compared to their counterparts. Studies elsewhere reported that partner involvement in ANC increases the mother's knowledge of neonatal danger signs. ${ }^{21,38}$ Participating husbands in maternal health service and reproductive health helps a mother in relieving the worry, discomfort and anxiety associated with gestation and postpartum problems. ${ }^{39,40}$ In addition, information being missed by the mother about neonatal health might be addressed by the husband.

This study also showed that media exposure had a positive association with mother's knowledge of neonatal danger signs. Media exposed mothers were 2.85 times more likely to be knowledgeable compared to those who did not have exposure to media. This result is consistent with studies conducted in Wolkite town ${ }^{10}$ and Fogera district, Ethiopia. ${ }^{21}$ This might be due to the government of Ethiopia gives great attention to the improvement of maternal, neonatal and child health through different mass media. $^{41}$

Mother's knowledge of neonatal danger sign increases with increasing parity. The current study found that mothers who had a parity of four and above were 2.46 times more likely to have good knowledge of neonatal 
danger signs compared to those mothers who deliver only once. This was supported by a study conducted in Bangladesh. ${ }^{32}$ Researches showed that increased parity is associated with delivery by skilled birth attendants ${ }^{42}$ and delivery in a health institution, ${ }^{43}$ which are enabling factors for knowledge of neonatal danger signs. Also, as parity increases getting information about neonatal danger signs in each pregnancy increases and neonates might develop one of the danger signs, and afterwards, mothers may not forget those danger signs. Furthermore, mothers whose recent neonate had developed danger signs were 1.83 times more likely to have good knowledge of neonatal danger signs compared to mothers whose neonates did not develop the danger signs. A similar finding was reported from a study conducted in Ambo town, Ethiopia. $^{17}$

Mothers who had good knowledge of neonatal danger signs were four times more likely to have appropriate healthseeking practices for neonatal danger signs compared to mothers who have had poor knowledge of neonatal danger signs. Studies conducted in Tiro Afeta district in Ethiopia ${ }^{31}$ and Al-Karkh district in Baghdad reported the role of knowledge of NDS on better healthcare-seeking. ${ }^{18}$ This is because good knowledge of danger sign is an important childcare tool having wide range of benefits for the child development and safeguard against morbidities and mortalities. ${ }^{27}$ This is because of the capacity to comprehend the seriousness of the illness for the neonate.

Mother's decision-making power is another important factor significantly associated with appropriate healthseeking practice for neonatal danger signs. Mothers with full decision-making power were 4.35 times more likely to have appropriate healthcare-seeking practice for their sick neonates compared to mothers who had less decision-making power. This finding is in agreement with a study conducted in Tenta district, northeast Ethiopia, in which autonomous mothers be present at child health-related discussions freely. ${ }^{28}$ Besides, women's autonomy is associated with increased intra-spousal communication, birth preparedness and readiness for complications ${ }^{46}$ and utilization of maternal health services which in turn scale up mothers' health-seeking practices for neonatal danger signs. $^{47}$

Our study found that mothers who got husband involvement were 3.53 times more likely to practice appropriate healthcare-seeking for neonatal danger signs compared to their counterparts. This might be because husband involvement increases freedom of movement and economy, open discussion and common understanding between the couples regarding maternal and neonatal healthcare utilization.

\section{Conclusion}

The knowledge of mothers on neonatal danger signs was found to be low despite having a reasonable level of health-seeking practices for neonatal danger signs. Mother's higher education, increased parity, exposure to mass media, husband involvement and having adequate birth preparedness were the factors that contribute to having a good knowledge of neonatal danger signs. Furthermore, mother's autonomy, husband involvement, exposure to media and having good knowledge of neonatal danger signs were independently associated with appropriate health-seeking practices for neonatal danger signs.

Accordingly, all concerned stakeholders should work to increase the husband involvement in neonatal and children's health, mother's decision-making power and education to buildup knowledge of neonatal danger signs and health-seeking practices.

\section{Limitation of the Study}

There may have been some recall bias. This may underestimate the knowledge and health-seeking practices of mothers for neonatal danger signs. Hence, the study includes all mothers who gave birth in the last year.

\section{Abbreviations}

AOR, adjusted odds ratio; ANC, antenatal care; CI, confidence interval; COR, crude odds ratio; ETB, Ethiopian Birr; HEWs, health extension workers; MNCHs, maternal, neonatal and child health; NDS, neonatal danger signs; PNC, postnatal care; SDG, sustainable development goal; SPSS, statistical package for social science.

\section{Data Sharing Statement}

The datasets collected and analyzed for the current study are available from the corresponding author and can be obtained on a reasonable request.

\section{Acknowledgments}

We would like to thank the University of Gondar for providing study ethical clearance and financial support. Our gratitude also goes to all data collectors and study participants. We are glad to Debretabor Town Health Office for writing permission letter. 


\section{Author Contributions}

All the authors had significant involvement in the conception and designing the study, acquisition of data, analysis and interpretation of data, took part in drafting the article, revising the article, gave final approval of the version to be published, have agreed on the journal to which the article has been submitted and agree to be accountable for all aspects of the work.

\section{Disclosure}

The authors declare that they have no conflict of interest for this work.

\section{References}

1. WHO, World Bank group and United nations. Clinical signs that predict severe illness in children under age 2 months: a multicentre study. Lancet. UNICEF; 2008;371:135-142. doi:10.1016/S0140-6736 (08)60106-3

2. NNF Teaching Aids: Newborn. Danger signs in a newborn. :1-6. Available from: http://www.newbornwhocc.org/pdf/teaching-aids/dan gersigns.pdf. Accessed August 12, 2020.

3. Rahim F, Jan A, Mohummad J, Iqbal H. Pattern and outcome of admissions to neonatal unit of khyber teaching hospital, peshawar. Pakistan Journal of Medical Sciences. 2007.

4. Hug L, Alexander M, Danzhen You LA. National, regional, and global levels and trends in neonatal mortality between 1990 and 2017, with scenario-based projections to 2030: a systematic analysis. Lancet Glob Heal. 2019;7(6):e710-20. doi:10.1016/S2214-109X(19)30163-9

5. UNICEF, WHO, World Bank and U-DPD. Levels \& trends in estimates developed by the UN inter-agency group for child mortality estimation united nations levels \& trends in child mortality. Maternal, Newborn, Child and Adolescent Health. 2017.

6. Afolabi BM. Sub-Sahara African Neonates Ghosts Stat. Journal of Neonatal Biology. 2017;6(1):1-3. doi:10.4172/2167-0897.1000246

7. Ethiopian mini demographic and health survey. Ethiopian Mini Demographic Health Survey. Ethiopian Public Health Institute. Journal of neonatal biology. Maryland UCAI, editor. Ethiopia, and Rockville: Addis Ababa; 2019.

8. WHO. Recommendations on Postnatal Care of the Mother and Newborn; 2013.

9. Jemberia MM, Berhe ET, Mirkena HB, Gishen DM, Tegegne AE, Reta MA. Low level of knowledge about neonatal danger signs and its associated factors among postnatal mothers attending at Woldia general hospital, Ethiopia. Matern Heal Neonatol Perinatol. 2018;4 (1):5. doi:10.1186/s40748-018-0073-5

10. Anmut W, Fekecha B, Demeke T. Mother's knowledge and practice about neonatal danger signs and associated factors in Wolkite Town, Gurage Zone, SNNPR, Ethiopia. J Biomed Sci. 2017;06(05):1-7. doi:10.4172/2254-609X.100077

11. Degefa N, Diriba K, Girma T, et al. Knowledge about neonatal danger signs and associated factors among mothers attending immunization clinic at arba minch general hospital, southern ethiopia: a cross-sectional study. Biomed Research International. 2019;2019:1-9.

12. Ekwochi U, Ndu IK, Osuorah CDI, et al. Knowledge of danger signs in newborns and health seeking practices of mothers and care givers in Enugu state, South-East Nigeria neonatology and fetal medicine. Ital J Pediatr. 2015;41(1):1-7. doi:10.1186/s13052-015-0127-5
13. Herbert HK, Lee ACC, Chandran A, Rudan I, Baqui AH. Care seeking for neonatal illness in low- and middle- income countries: a systematic review. Plos Medicine. 2012;9:3.

14. Nsibande D, Doherty T, Ijumba P, et al. Assessment of the Uptake of Neonatal and Young Infant Referrals by Community Health Workers to Public Health Facilities in an Urban Informal Settlement. South Africa: KwaZulu-Natal; 2013:1-8.

15. Chou D, Daelmans B, Jolivet R, Mary Kinney A, Say L. Ending preventable maternal and newborn mortality and stillbirths. Women's, Child Adolesc Heal. 2010;19-22.

16. Nigatu T, Id B, Worku AG, Yalew AW, Bikis A, Kebede ZT. Mothers treatment seeking intention for neonatal danger signs in northwest Ethiopia: A structural equation modeling. Plos One. 2018;1-15.

17. Bulto GA, Fekene DB, Moti BE, Demissie GA. Knowledge of neonatal danger signs, care seeking practice and associated factors among postpartum mothers at public health facilities in Ambo town, Central Ethiopia. BMC Res Notes. 2019;1-7.

18. Abdulrida H, Hassan R, Sabri M. Knowledge and health-seeking practices of mothers attending primary health-care centers in baghdad al-karkh sector about danger signs in newborns. Mustansiriya Med J. 2018;17(1):29. doi:10.4103/MJ.MJ_7_18

19. Than KK, Morgan A, Pham MD, Beeson JG. Determinants of knowledge of critical danger signs, safe childbirth and immediate newborn care practices among auxiliary midwives: a cross sectional survey in Myanmar. BMJ open. 2017;1-10.

20. Sandberg J, Pettersson KO, Asp G, Kabakyenga J, Agardh A. Inadequate knowledge of neonatal danger signs among recently delivered women in southwestern rural Uganda: A community survey. PLoS One. 2014;9:5. doi:10.1371/journal.pone.0097253

21. Asnakew DT, Engidaw MT, Gebremariam AD. Level of knowledge about neonatal danger signs and associated factors among mothers who delivered at home in Fogera District, South West, Ethiopia. Biomed Stat. 2019;3(4):53-60.

22. Nigatu SG, Worku AG, Dadi AF. Level of mother's knowledge about neonatal danger signs and associated factors in North West of Ethiopia: a community based study. BMC Res Notes. 2015;8(1):4-9. doi:10.1186/s13104-015-1278-6

23. Adem N, Berhe KK, Tesfay Y. Awareness and associated factors towards neonatal danger signs among mothers attending public health institutions of mekelle City, Tigray, Ethiopia, 2015. J Child Adolesc Behav. 2017;05:06. doi:10.4172/2375-4494.1000365

24. Mersha A. Mother's level of knowledge on neonatal danger signs and its predictors in Chencha District, Southern Ethiopia. Am J Nurs Sci. 2017;6(5):426. doi:10.11648/j.ajns.20170605.17

25. Yadeta TA. Antenatal care utilization increase the odds of women knowledge on neonatal danger sign: a community-based study, eastern Ethiopia. BMC Res Notes. 2018;11(1):845. doi:10.1186/s13104-018-3957-6

26. Lancet T, Health G, Lancet T, Health G. Comment introducing the lancet global health commission on high-quality health systems in the SDG Era. The Lancet Global Health. 2017;480-481.

27. Anwar-ul-Haq, Durrani HM, Kumar R, Durrani SM. Recognizing the danger signs and health seeking behaviour of mothers in childhood illness in Karachi, Pakistan. Univers J Public Heal. 2015;3(2):49-54.

28. Molla G, Gonie A, Belachew T, Admasu B. Health care seeking behaviour on neonatal danger signs among mothers in Tenta District, Northeast Ethiopia: community based cross- sectional study. International journal of nursing and midwifery. 2017;9 (July):85-93.

29. Andarge E, Nigussie A, Wondafrash M. Factors associated with birth preparedness and complication readiness in Southern Ethiopia: a community based cross-sectional study. BMC pregnancy and Childbirth. 2017;1-13.

30. Markos D, Bogale D. Birth Preparedness and Complication Readiness Among Women of Child Bearing Age Group in Goba Woreda. BMC pregnancy and Childbirth. Oromia region, Ethiopia; 2014:1-9. 
31. Kuganab-Lem R, Yidana A. Exploring women knowledge of newborn danger signs: A case of mothers with under five children. Public Heal Res. 2014;4(5):195-202.

32. Alex-Hart B, Dotimi D, Opara P. Mothers' recognition of newborn danger signs and health seeking behaviour. Niger J Paediatr. 2014;41 (3):199. doi:10.4314/njp.v41i3.9

33. Kibaru EG, Otara AM. Knowledge of neonatal danger signs among mothers attending well baby clinic in Nakuru Central District, Kenya: cross sectional descriptive study. BMC Res Notes. 2016;9(1):1-8. doi:10.1186/s13104-016-2272-3

34. Molla G, Miskir Y, Belachew A. Knowledge of neonatal danger signs among recently delivered mothers in Mekedella woreda, Northeast Ethiopia, in 2017: a cross- sectional study. Public Health. 2020;180:85-89. doi:10.1016/j.puhe.2019.11.016

35. Nonyane BA, Kazmi N, Koffi AK, et al. Factors associated with delay in care-seeking for fatal neonatal illness in the Sylhet district of Bangladesh: results from a verbal and social autopsy study. $J$ Glob Health. 2016;6:1. doi:10.7189/jogh.06.010605

36. Kanti S, Id C, Billah SM, El AS. Care-seeking practices for sick neonates: findings from cross-sectional survey in 14 rural sub-districts of Bangladesh. Plos one. 2018;1-12.

37. Turyakira E, Pettersson KO. Influence of birth preparedness, decisionmaking on location of birth and assistance by skilled birth attendants among Women in South-Western Uganda. Plos one. 2012;7:4.

38. Bin ZS, Das GR, Muhammed G, Kibria A, Hossain N. Husband ' $s$ involvement with mother' $\mathrm{s}$ awareness and knowledge of newborn danger signs in facility - based childbirth settings: a cross - sectional study from rural Bangladesh. Plos one. 2018;4-9.

39. Yue K, Donnell CO, Sparks PL. Patient Education and Counseling The effect of spousal communication on contraceptive use in Central Terai, Nepal. Patient Educ Couns. 2010;81(3):402-408. doi:http://dx. doi.10.1016/j.pec.2010.07.018.
40. Redshaw M, Henderson J. Fathers 'engagement in pregnancy and childbirth: Evidence from a national survey. BMC pregnancy and childbirth. 2013.

41. National Technical Guidance for Maternal and Perinatal Death Surveillance and Response. Ethiopian public health institute. Ethiopian public health institute; 2017.

42. Bin ZS, Hossain N, Hussain MA, Abimanue V. Factors related to knowledge on newborn danger signs among the recently delivered women in sub- district hospitals of Bangladesh. Public Heal Indones. 2017;3(2):50-60. doi:10.36685/phi.v3i2.121

43. Olakunde BO, Adeyinka DA, Mavegam BO, Olakunde OA, Yahaya HB. Factors associated with skilled attendants at birth among married adolescent girls in Nigeria: evidence from the multiple indicator cluster survey, 2016/2017. International health. 2019;545-550.

44. Ndao-brumblay SK, Mbaruku G, Kruk ME. Parity and institutional delivery in rural Tanzania: a multilevel analysis and policy implications. Health Policy and Planning. 2013. 2012. 647-657

45. Melkamu B, Berhane M, Yimam H, Jibat N, Zewdu M. Parents , knowledge of danger signs and health seeking behavior in newborn and young infant illness in tiro afeta district, southwest ethiopia: a community-based study. International health. Ethiop J Heal Sci. 2018;28(July):473-482.

46. Osamor P, Grady C. Decision-making autonomy: empirical evidence from nigeria. Journal of biosocial science. 2018;50(1):70-85.

47. Pandey KK, Singh RD. Womens status, household structure and the utilization of maternal health services in Haryana (India). Journal of statistics applications and probability letters. 2017;10(1):1-10.

\section{Publish your work in this journal}

Research and Reports in Neonatology is an international, peerreviewed, open access journal publishing original research, reports, editorials, reviews and commentaries on neonatal health. The manuscript management system is completely online and includes a very quick and fair peer-review system. Visit http://www.dovepress. com/testimonials.php to read real quotes from published authors. 